Orbis Tertius, vol. XXV, $\mathrm{n}^{\circ}$ 32, e172, noviembre 2020-abril 2021. ISSN 1851-7811

Universidad Nacional de La Plata

Facultad de Humanidades y Ciencias de la Educación

Centro de Estudios de Teoría y Crítica Literaria

\title{
Entre la fascinación y el terror. La escritura del cine argentino de $E I$ desencuentro a La traición de Rita Hayworth
}

\author{
Between fascination and terror. The writing of argentine cinema from El \\ desencuentro to La traición de Rita Hayworth
}

Lea Hafter

leahafter@gmail.com

Universidad Nacional de La Plata. Programa de Crítica Genética y Archivos de Escritores. IdIHCS (UNLPCONICET), Argentina

Cita sugerida: Hafter, L. (2020). Entre la fascinación y el terror. La escritura del cine argentino de El desencuentro a La traición de Rita Hayworth. Orbis Tertius, 25(30), e172. https://doi.org/10.24215/18517811e172

\begin{abstract}
Resumen: El cine en la obra de Manuel Puig es un tema vertebrador. Sin embargo, poco se ha dicho acerca de la presencia del cine argentino en su obra. A partir los manuscritos de La traición de Rita Hayworth y del archivo del escritor se propone una lectura, en clave de experiencia cinematográfica, de las películas argentinas que forman parte de la génesis de la novela.
\end{abstract}

Palabras clave: Manuel Puig, La traición de Rita Hayworth, Manuscritos, Cine Argentino.

\begin{abstract}
Cinema in Manuel Puig's work is a central theme. However, little has been said about the presence of Argentine cinema in his work. Based on the manuscripts of La traición de Rita Hayworth and the writer's archive, a reading, based on cinematographic experience, of the argentine films that are part of the genesis of the novel is proposed.
\end{abstract}

Keywords: Manuel Puig, La traición de Rita Hayworth, Manuscripts, Argentine Cinema.

\section{Cine: FANTASÍAS Y PESADILLAS}

Una mujer se presenta entre otras tantas postulantes para trabajar en un cabaré, lo hace por su hijo. Es madre soltera, en la década del treinta, en Buenos Aires. Logra el puesto, es hermosa y se distingue entre las otras ante los ojos del dueño del lugar. Todo marcha bien, entre elaborados cuadros musicales y pasos de comedia, hasta que el padre del niño aparece una de las noches en el salón. Quiere llevárselo, y la exigencia termina en secuestro. El secuestro de un niño en medio de la noche de año nuevo: todos duermen en la casa, una mano rompe el vidrio y abre la ventana; sobre el niño dormido crece la sombra de un hombre. Cuando los otros habitantes de la casa se despiertan la cámara vuelve sobre la cama del niño, ahora vacía. Desde un cuarto de hotel, al teléfono - por supuesto- la madre rompe en un llanto desgarrador, ha recibido la peor noticia. El pasaje, que dura apenas unos minutos, corresponde a una de las escenas finales de Cuatro corazones, película argentina estrenada en 1939, con la dirección de Enrique Santos Discépolo y Carlos Schlieper. Es una comedia donde todo se resuelve felizmente y, quizás justamente por eso, el episodio se recorta levemente del resto del film.

En La traición de Rita Hayworth, Toto -también en 1939- tiene miedo, a ver si un gitano se lo lleva: “¿es cierto, Felisa? 'un gitano malo cara de carbón con brazo peludo que roba a los chicos que están bien vestidos 
y se han escapado" (Puig, 2011 [1968], p. 31); la fantasía toma forma "Felisa ¿̨detrás de la puerta? el gitano pone a un chico en la bolsa y en la calle no se dan cuenta" (Puig, 2011, p. 32), los gitanos, dice Felisa, "ya se fueron de Vallejos, pero queda uno que roba los chicos" (Puig, 2011, p. 32); por eso, piensa Toto, "los nenes más chicos no deben decir mentiras porque les crece atrás una cola larga como a los monitos y entonces sí que es fácil que me agarre el gitano me enlaza la cola y listo" (Puig, 2011, p. 33), la madre aparece entonces en la escena de esta aterradora fantasía: "Pero al que lo agarran los gitanos la madre no lo conoce más porque lo pintan de carbón" (Puig, 2011, p. 43), si el gitano se lo lleva "mamá me está buscando porque ya es la hora de ir al cine? mamá me busca y no me encuentra adentro?" (Puig, 2011, p. 43), "mami me estará esperando adentro sentada en la butaca ¡entonces yo grito para que me venga a salvar!” (Puig, 2011, p. 44). Los papeles conservados que dan cuenta fragmentaria del proceso de escritura de la novela muestran que este es uno de los temas sobre los que el autor, Manuel Puig, vuelve una y otra vez. Así, el miedo a ser llevado es reelaborado con lápiz, con tinta, a máquina, a uno y otro lado de la hoja. ${ }^{1}$

En Vallejos, Toto no mira películas argentinas junto a Mita. Pero Coco sí, junto a Male, en Villegas. Se trata entonces de poner en suspenso una lectura en clave autobiográfica para vislumbrar la distancia que media entre un recuerdo y la escritura. Así, volver sobre el archivo permite leer en el diálogo, por ejemplo, entre aquella comedia de los años treinta y el miedo a los gitanos, en un gesto que recorre y reconoce qué es lo que habita allí, ese resto que la visualización de una película habilita en la escritura.

\section{UNA HISTORIA DE DESENCUENTROS}

La traición de Rita Hayworth materializa el ingreso de Manuel Puig a la literatura. La historia de este comienzo - "el accidente de las treinta páginas de banalidades" (Puig, 1985, p. 7) - es referida por el mismo autor en varias ocasiones, convirtiéndose en objeto de diferentes lecturas críticas (Giordano, 1996; Goldchluck, 212). Por su parte, el proceso de escritura de esta primera novela, segn puede recomponerse a partir de las cartas familiares, abarca inicialmente un período que va desde el año 1962 hasta $1965 .^{2}$ Además, esas mismas cartas guardan el nombre preliminar de la obra: "estoy enloquecido con la cuestión [de la editorial] Einaudi. Si 'El desencuentro' (título pavo pero no encuentro otro) gustó a la lectora de Einaudi (...), quiere decir que MARCHAR con todo el mundo" (Puig, 25, p. 163) escribe desde Nueva York el 3 de junio de 1965, cuando el proyecto se encuentra en una etapa avanzada. Varios meses después, en noviembre, comenta en otra carta "Me he desentendido de todo, no me preocupa tanto la suerte de 'El desencuentro', título final del manuscrito (como lo llama [Juan] Goytisolo)" (Puig, 2005, 185), y reafirma este nombre semanas más tarde: "Aparte de esto siempre acaricio la esperanza de que suceda algo estrambótico con 'El desencuentro' (título que me convence por sencillo y medio tanguero)” (Puig, 25, p. 189). Sin embargo, la novela tendrá como título definitivo, La traición de Rita Hayworth, cuando quede entre las finalistas de la edición del concurso Seix Barral de ese mismo año, $1965,{ }^{3}$ tal como relata el autor a su familia en una carta fechada en enero del año siguiente, en el que describe lo sucedido a finales de diciembre: "Los dos que votaron por mí hasta el final fueron Castellet y el hermano de Goytisolo [Luis], que también es escritor. El título lo eligieron ellos, de uno de cinco títulos que yo les había dado, pero a mí no me gusta” (Puig, 25, p. 22).

Más allá de la anécdota, el pasaje de un título -El desencuentro- a otro -aquel con el que finalmente será publicada la novela - parece terminar de dar forma a un fenómeno que se advierte ya en el proceso de escritura -entendida como reescritura (Lois, 2005, p. 56)-, algo que se lee en los manuscritos y que implica, como señala Goldchluk (2012), un deslizamiento de lo particular a lo universal. En otras palabras, el título $E l$ desencuentro aloja los resabios de una obra marcada por una voluntad narrativa inicial que pretende imprimir en la palabra escrita cada detalle de lo vivido; se trata de resabios porque progresivamente, en cada reescritura -y no únicamente en la versión provisoriamente final- esa materia biográfica se ha ido convirtiendo en otra cosa, que es a su vez lo mismo pero diferente, La traición de Rita Hayworth. En el cambio de nombre se 
lee a la vez que se consensa la afirmación de un cambio de dirección que ya había sucedido en el texto; un cambio que no se lee en un sentido teleológico, en tanto no se concibe como un resultado inevitable (Lois, $2005)^{4}$. La aceptación de ese nuevo nombre es un gesto de abandono de aquella escritura tan precisa como dolorosa y necesaria que en cierto modo le permitiría al autor comenzar a ser Manuel Puig. Del mismo modo en que el escritor Juan Manuel Puig que había firmado los guiones hasta ese momento se convierte en el Manuel Puig que presenta la novela, abandonando en ese gesto el nombre recibido para adoptar una firma de escritor, así también una escritura apegada a la historia personal termina de convertirse en novela (en algo nuevo) cuando es bautizada por otro escritor. Así, a medida que reescribe cada una de esas voces, se reelabora y progresivamente universaliza aquella experiencia de un pueblo de provincia. En este sentido, el cambio de los nombres biográficos de los personajes en la etapa final de redacción de la novela, ${ }^{5}$ sería un elemento entre tantos otros, un detalle que evidencia la transformación que el texto ya había experimentado, antes que un contundente gesto de alejamiento de la voluntad autobiográfica. De algún modo, leer LTRH en clave de autobiografía novelada impide u obtura entender los desplazamientos anteriores que operan allí y que habilitan el repertorio de recursos característicos de la narrativa de Puig, entre los que se cuenta esa distorsión narrativa con la que se distancia del referente (una película, una anécdota) que es, en otras palabras, experiencia transmutada. Lo que borra lo reescribe y permanece, pero se transforma. En el caso de $L T R H$ los nombres pueden cambiar una vez que todo ha cambiado, aunque nada desaparezca. De esta manera, ese “alejamiento paulatino de un relato autobiográfico", que José Amícola (1996, p. 13) lee en la obra de Manuel Puig puede rastrearse en la etapa pretextual de esta primera novela. De algún modo, en El desencuentro, en ese conjunto de papeles conservados, y sobre todo en las primeras versiones de los capítulos iniciales, en esa materia reelaborada, persiste el escritor que Manuel Puig decide no ser. Hay allí dos comienzos, una primera novela que tiene en su devenir una nueva novela. Esto no significa, sin embargo, que se trate de dos novelas; El desencuentro tampoco se reduce a un conjunto de borradores para "entender" $L T R H$, porque

...el manuscrito se desarrolla en un tiempo y una lógica heterogéneos; es otro, pero no es ajeno, establece con ese otro estado de archivación, con esa otra huella de creación que es un texto publicado en alguna de sus posibilidades, un diálogo. No va a narrar la historia del texto ya que no es su causa directa, pero en cambio podrá mostrar un campo de tensiones irresueltas (Goldchluk, 2017, p. 157).

El manuscrito es, una vez más, el otro del texto.

\section{INICIOS GUARDADOS}

Entre la vasta cantidad de papeles conservados que pertenecen a la etapa pretextual de $L T R H$ se hallan distintas versiones de los capítulos; ${ }^{6}$ tres son las que pertenecen al episodio donde Toto da forma a la pavorosa fantasía de un secuestro, a la par que despliega una temprana fascinación por el cine, ${ }^{7}$ tema central ya en la primera versión, como puede leerse en este fragmento donde el personaje relata detalladamente: 


\section{FIGURA 1}

[Detalle] (LTRH, ID puig.NLtrh.N.A.7.0120_(4C))

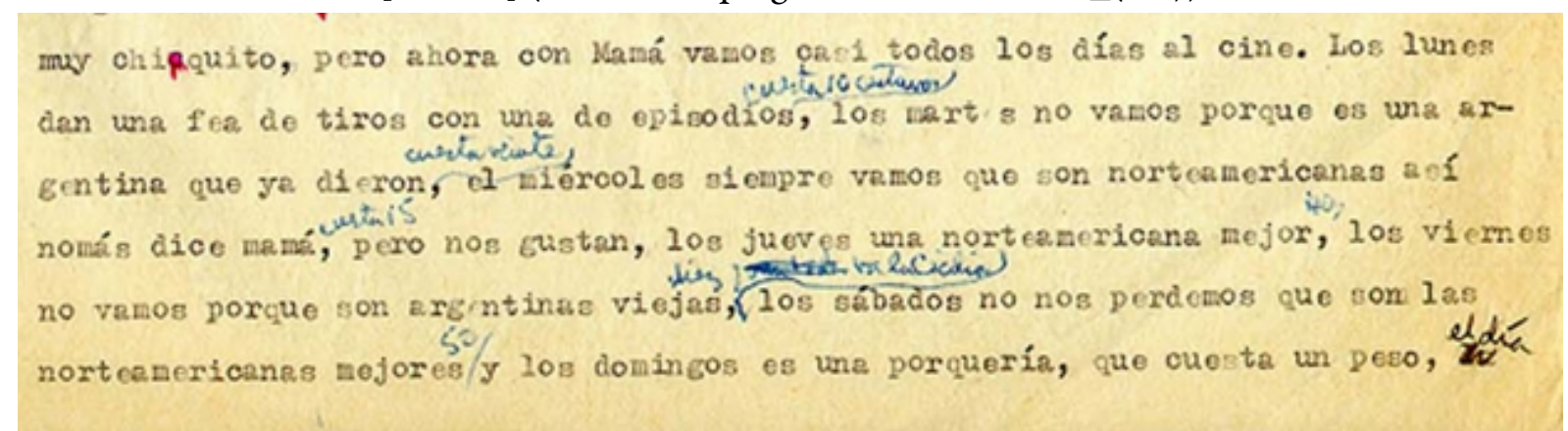

FIGURA 2
[Detalle] (LTRH, ID puig.NLtrh.N.A.7.0121_(5C))

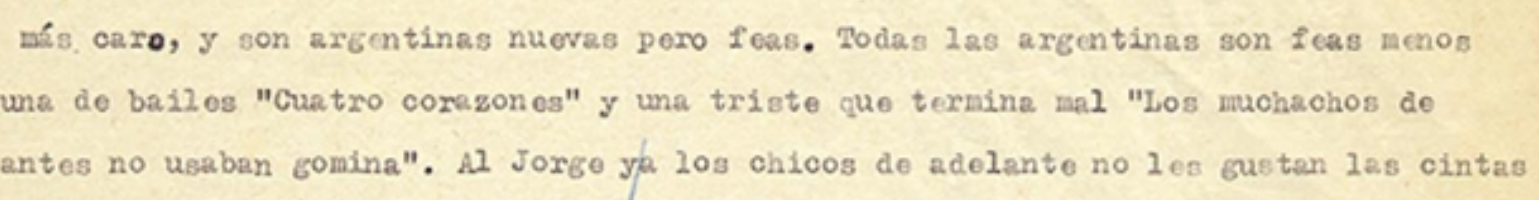

muy chiquito, pero ahora con Mamá vamos casi todos los días al cine. Los lunes dan una fea de tiros con una de episodios, cuesta 10 centavos, los martes no vamos porque es una argentina que ya dieron, cuesta veinte, el miércoles siempre vamos que son norteamericanas así nomás dice mamá, cuesta 15, pero nos gustan, los jueves una norteamericana mejor, 40, los viernes no vamos porque son argentinas viejas, diez, y van todos va la Cecilia, los sábados no nos perdemos que son las norteamericanas mejores, 50 , y los domingos es una porquería, que cuesta un peso, ta el día más carzo, y son argentinas nuevas pero feas. Todas las argentinas son feas menos una de bailes "Cuatro corazones" y una triste que termina mal "Los muchachos de antes no usaban gomina". Al Jorge y a los chicos de adelante no les gustan las cintas

Este pasaje, que abarca el final de una hoja y el comienzo de la siguiente, por su temática y personajes, no resultaría ajeno para el lector de $L T R H$, pero si buscara el equivalente de este fragmento en la novela publicada no lo encontraría, ya que en las sucesivas reescrituras el mismo se disemina progresivamente y hasta podría afirmarse incluso que termina por desaparecer; sin embargo, en tanto "lo incinerado ya no es nada salvo la ceniza, un resto cuyo deber es no quedar, ese lugar de nada, un lugar puro aunque se esconda” (Derrida p. 23) esto no es lo que sucede.

Dos cuestiones aparecen alojadas en este breve fragmento, o más precisamente en su progresivo devenir. Ambas residen en el cruce de dos aspectos característicos de la escritura de Manuel Puig -y de la escritura de esta novela en particular: el cine en un sentido amplificado y la utilización de material biográfico; ambos convergen en la experiencia cinematográfica. En primer lugar aparece lo que podría denominarse un desanclaje, recurso que propicia el distanciamiento con la voluntad de una escritura que se pretende calcada de la experiencia. En segundo término, pero en estrecha relación con lo anterior, se evidencia un ocultamiento/ transmutación del cine nacional.

\section{Desanudar EL TIEMPO}

Por un lado, entonces, entre la presencia de este fragmento donde el personaje puntualiza algunos detalles de las idas al cine con su madre y su ausencia en el texto publicado en 1968 -y el finalizado en 1965- aparecen las huellas de un progresivo distanciamiento del relato autobiográfico. ${ }^{8}$ En la imagen del 
manuscrito puede observarse sobre la escritura a máquina un agregado a mano, en tinta azul, que repone los precios de cada una de las funciones semanales ("cuesta 10 centavos", "cuesta veinte", "cuesta 15”, “40”, "diez", "50"); el narrador amplía de este modo la información inicial, que en un primer momento se centraba exclusivamente en la clasificación de las películas a partir de criterios tales como procedencia ("argentina”), género ("tiros", "bailes”), actualidad ("que ya dieron", "nuevas", "viejas") y gusto de la pareja de espectadores ("una fea”, "una así nomás", "mejor”, "una porquería”). Esta operación de añadido repone el valor de las entradas propiciando una incorporación de supuestos detalles reales de la experiencia vivida, lo que anclaría el texto al año en que las entradas costaban eso. Sin embargo aquello que se suma, luego se abandona, esa precisión que mediante el agregado del precio de las funciones anuda la ida al cine de un niño con su madre a un tiempo específico, termina deshaciéndose. Dicho de otro modo, en la escritura vemos el tiempo que va y que vuelve: el valor de la entrada es un elemento que agrega lo que de alguna manera haría más "característico" el relato, más cercano a un registro costumbrista, y así, al quitar lo que en una primera instancia fue añadido, se exhibe que ese detalle, aquel que aparentemente muestra y recupera más cabalmente la experiencia, no es necesario, aunque fue preciso recurrir a él. Lo que resuena como verdadero de esa experiencia no necesita reponer esos datos, sin embargo el camino es transitado en una labor y una actitud, en términos de Walter Benjamin, semejantes a la del "hombre que excava” (2011, p. 128). ${ }^{9}$ Entre la versión primera y el texto publicado la experiencia del cine se desancla temporalmente, esto permite actualizar la lectura y presentificar la experiencia del cine. Esta presentificación se refuerza, además, al eliminar la información sobre el valor de las entradas en tanto elemento jerarquizador, puesto que en la información del párrafo los precios imprimen una jerarquía sobre las películas que se proyectan, provocando que no todo el cine sea igual, pero cuando esto se borra pasa a ser, sí, todo el cine, en cualquier tiempo; es un niño yendo al cine con su madre. Por supuesto, la preferencia de los personajes por cierto tipo de producciones cinematográficas se construye en el relato, pero no ya mediante estos recursos. Hay, entonces, un desanudar el tiempo; a media que se narra y se vuelve a contar, la experiencia del sujeto permanece en el pasado y se trae lo verdadero, lo que resuena, no se accede al pasado sino a lo que en nuestro tiempo resuena de ese pasado (Benjamin, 2009). ${ }^{10}$

\section{NADA MÁs QUE UN PAR DE PELÍ́CULAS ARGENTINAS}

El cine en la obra de Manuel Puig, es preciso decirlo, resulta un tema más que transitado. Sin embargo, poco se ha dicho sobre su relación con el cine argentino, puntualmente, acerca de la mención de un repertorio de títulos e intérpretes argentinxs en su escritura, ${ }^{11}$ antes que sobre la adaptación al medio audiovisual de sus novelas. ${ }^{12}$

La fascinación por las divas y la pasión por las películas del cine de los años dorados de Hollywood, el amor por los musicales con sus coreografías apabullantes, todo eso se ha transformado en un eco que acompaña y resuena invariablemente tras el nombre Manuel Puig. En su primera novela todo esto resulta, por supuesto, un tema vertebrador, en tanto el mundo de Toto se articula en la palabra a partir de la presencia de ese cine: secuencias completas que en una narración transfigurada habilitan la voz y la experiencia del niño. Pero el cine argentino no aparece en boca del protagonista, y son únicamente dos las veces en que a lo largo de las páginas de $L T R H$ el universo cinematográfico nacional es aludido, y esto sucede a partir de la evocación de nombres de artistas. Por un lado, en "Casa de los padres de Mita", las voces dialogan sobre Carlos Palau:

-Vi la última película de Carlos Palau.

- Mita la va a ver cuando la den en Vallejos.

$-¿$ Cuánto tiempo estuvo de novia con Carlos Palau?

- Nunca nos imaginamos que Carlos Palau llegara a triunfar.

-Nunca estuvo de novia con Carlos Palau (...). 
-Él tiraba de las sogas detrás del escenario en el teatrito de la Municipalidad.

-Es el único galán bueno que tiene el cine argentino.

_El marido de Mita es idéntico a Carlos Palau, siempre lo dije. (Puig, 2011, p. 9)

La segunda mención llega en el capítulo IV, cuando Choli asegura: "todos los peinados de Mecha Ortiz me quedan bien. No hay artista que me guste más, entre las argentinas” (Puig, 2011, p. 52), y más adelante agrega: "cuando tengo ganas de verme bien, me pruebo la ropa de noche, con peinado alto, como el que sacaba Mecha Ortiz en la obra 'Mujeres'13" (Puig, 2011, p. 66). La primera de estas referencias, el nombre "Carlos Palau", es un nombre ficticio para designar al actor José Gola en el universo de la novela; la segunda, introduce el nombre de la actriz más admirada por Manuel Puig dentro del repertorio nacional, ${ }^{14}$ una diva que comparte el cielo de las estrellas con los nombres consagrados de las divas de Hollywood.

Pero en el caso del fragmento de la primera versión ya citado, sucede algo bastante diferente. En voz del niño protagonista solo aparecen mencionadas dos películas. El título de ambas, sorpresivamente para lo que se afirma sobre el cine en Puig, es de dos producciones argentinas, y en la detallada descripción del repertorio semanal proyectado en la pantalla del cine del pueblo no hay lugar para el nombre de producción extranjera alguna, ni siquiera de las "norteamericanas mejores", que sí son las preferidas de los protagonistas, y que aparecen diseminadas a lo largo del mismo capítulo. Las únicas películas que aparecen mencionadas aquí son entonces argentinas, y ambas resultan emblemáticas en la historia del cine nacional. Sin embargo, el título de ninguna de ellas figurará en la versión publicada, ya que progresivamente asistimos a su ocultamiento en el devenir de la escritura.

Cuatro corazones y Los muchachos de antes no usaban gomina son dos películas que forman parte de la época de oro del cine industrial argentino (Di Núbila, 1998). Ambas gravitan dentro del universo temático consolidado ya en las dos primeras películas sonoras, Tango! (Mogia Barth (dir.), 1933) y Los tres berretines (Equipo Lumiton (dirs.), 1933); y pertenecen a esa vertiente del melodrama tanguero que supo reafirmarse con la sistematización en serie, ${ }^{15}$ donde se refuerzan los rasgos ya presentes en el cine de la década anterior (Manetti, 2014, p. 26). Ambas, también, se ubican entonces del lado de El desencuentro, ese título "sencillo y medio tanguero".

Los muchachos..., estrenada en 1937, es una película escrita y dirigida por Manuel Romero. El guion, en colaboración con Mario Bernard, está basado en la obra homónima del mismo director. En un periódico especializado de la época, donde se califica a la película con "categoría EXTRAORDINARIA", se reseña de este modo su argumento:

Obedeciendo órdenes paternas, un muchacho rompe con su amante, para casarse con una joven de buena familia. Vive vegetando al lado de su esposa que no lo comprende y al llegar a la madurez, evoca con un amigo los tiempos pasados. En un cafetín de la Boca encuentra a su antigua amante, objeto de burla de los jóvenes inconscientes, entre los que se halla su hijo, el cual reacciona al ver la verdad y promete proteger a la anciana. (El Heraldo del cinematografista, 1937).

La amante mencionada en el texto no es otra que la rubia Mireya, el personaje popular que en este caso significó el debut en la pantalla grande de, justamente, Mecha Ortiz. Y si bien el título de este relato de desencuentros generacionales desaparece de las páginas de $L T R H$, la historia queda en más de un sentido alojada allí. Por otra parte, el nombre Manuel Romero así como el de esta película figuran en las listas cinematográficas (de films, actrices, actores y directores) que una y otra vez aparecen en el Archivo Puig. ${ }^{16}$ 
FIGURA 3

(PA, ID puig.NPa.N.E.28.0259V)

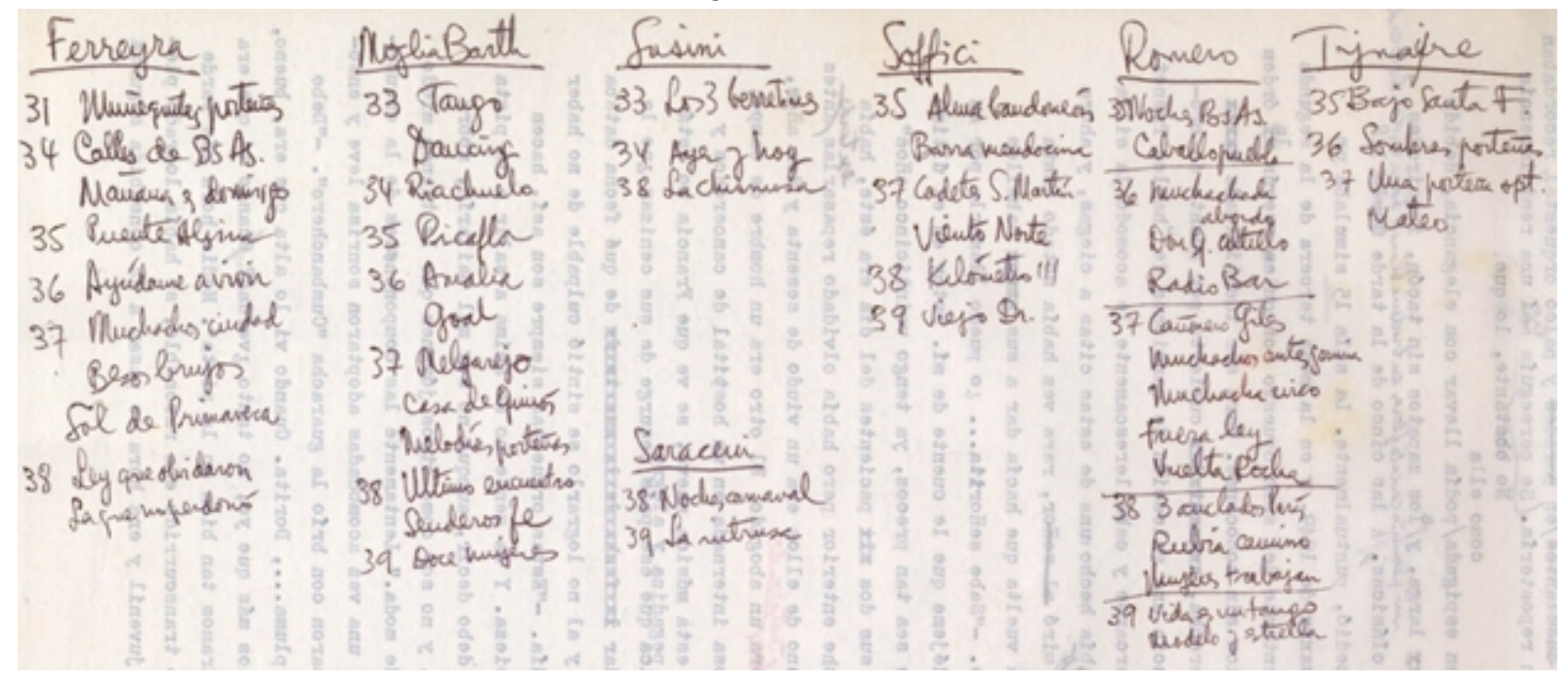

Esta inclusión resulta aún más interesante si se repone, por un lado, la resistencia que el director cinematográfico despertó a causa de las temáticas y elementos populares abordados en sus películas así como por su éxito comercial (Di Núbila, 1998); y por otro, la referencia a Los muchachos... en particular, habilita la posibilidad de un inesperado diálogo cuando se repone la reseña adversa que un joven Borges publicara en la revista Sur. ${ }^{17}$

FIGURA 4

Archivo Puig en proceso de incorporación (D.D.16.04_R)

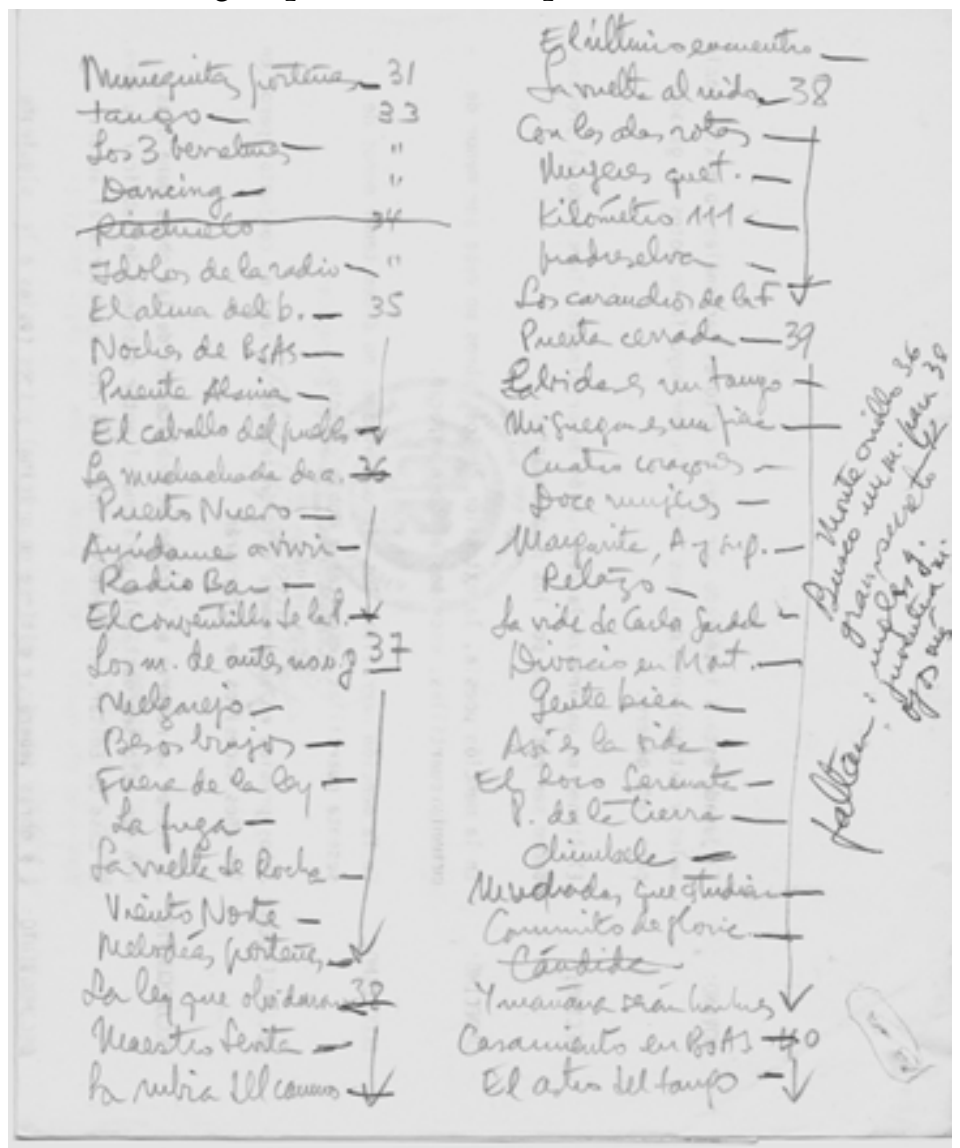


También Cuatro corazones (Discépolo/Schlieper, 1939) puede leerse en otra de estas listas, en la que por otra parte Los muchachos... vuelve a aparecer. La película, "una de bailes", abunda en números musicales complejos y da cuenta de una gran precisión en el manejo de planos medios y planos generales así como en la elaboración de pasajes con cámara picada; cómo no evocar El gran Ziegfeld (1936). En este sentido, si bien en la película resulta evidente la marca de Discépolo, quien además es protagonista, también es cierto que puede reconocerse el trabajo de Carlos Schlieper “en (...) la técnica cinematográfica [y] la puesta en escena”, algo que "se evidencia fundamentalmente en los números musicales, donde se pueden percibir algunos indicios de la influencia de Ernst Lubitsch" (Kelly Hopfenblatt, 2014). Además de dialogar con la pavorosa posibilidad de un secuestro, la película se inscribe en la lista de los musicales que Toto relata en $L T R H$.

De las dos películas quedan rastros, de una, resuena entre los musicales la fantasía terrorífica de un secuestro, de la otra, la huella de un gran desencuentro.

\section{FinAl. En EL INICIO, EL CINE}

El cine es y propone en la obra de Manuel Puig fantasías de toda clase. El cine y la felicidad, vía de escape a una realidad intolerable, pero también el cine y el miedo, matriz para las fantasías aterradoras o las pesadillas ocultas. Así fue también el ingreso del autor a este universo cuando en Villegas su padre, ante el miedo que le provoca al pequeño Coco la sala a oscuras, lo lleva a la cabina del proyeccionista para poder ver su primera película, La novia de Frankenstein (1935); y este será después el ritual favorito que compartirá con su madre. En LTRH Toto también se enfrenta al miedo, y aunque siempre es la madre la que aparece en esas escenas de fantasía relacionadas con el gitano y el secuestro, todo comienza porque Toto ha ido al Beneficio con su padre. Todo se desencadena por el miedo a ir solo al baño. A partir del problema al que se enfrenta el personaje cuando debe ir al baño durante un Beneficio al que acude con su padre se superpone una serie de elementos constitutivos: el cine, el secuestro, la sexualidad, la comida, la madre, el padre. Desenterrar para dejar ver lo real en las diferentes capas de tierra que deja una excavación al descubierto. Un poco eso es lo que sucede cuando se lee la experiencia cinematográfica inscripta a partir de la presencia de dos películas argentinas entre El desencuentro y La traición de Rita Hayworth. 


\section{REFERENCIAS}

Amícola, J. (Comp.). (1996). Manuel Puig: Materiales iniciales para La traición de Rita Hayworth. La Plata, Argentina: UNLP. FAHCE. Centro de Estudios de Teoría y Crítica Literaria.

Benjamin, W. (2009). Tesis sobre la historia y otros fragmentos. Rosario, Argentina: Prohistoria ediciones.

Benjamin, W. (2011). Denkbilder. Epifanias en viajes. Buenos Aires, Argentina: El Cuenco de Plata.

Borges, J. L. (1937). Dos films. Sur (31), 101.

De Diego, J. L. (2000). La novela de aprendizaje en Argentina: 2da. parte. Orbis Tertius (7), 15-31. Recuperado de ht tp://www.memoria.fahce.unlp.edu.ar/art_revistas/pr.2832/pr.2832.pdf

Derrida, J. (2009). La difunta ceniza. Buenos Aires, Argentina: La Cebra.

Di Núbila, D. (1998). La época de oro. Historia del cine argentino I. Buenos Aires, Argentina: Ediciones del Jilguero.

Giordano, A. (1996). Manuel Puig: Los comienzos de una literatura menor. Orbis Tertius (2-3), 255-274. Recuperado de http://www.memoria.fahce.unlp.edu.ar/art_revistas/pr.2500/pr.2500.pdf

Goldchluk, G. (2012). Manuel Puig: el suceso de la escritura. La Biblioteca (12), 332-342.

Goldchluk, G. (2017). Rutas de la genética. En A. Martínez, Y. Gonzalo y N. Busalino (Coords.), Rutas dela Lingúistica en la Argentina II. La Plata, Argentina: UNLP. FaHCE. Recuperado de http://www.libros.fahce.unlp.edu.ar/i ndex.php/libros/catalog/book/86

Kelly Hopfenblatt, A. (2014). Fiesta, deseo y burguesía: Carlos Schlieper y la alegría de vivir. El ángel exterminador (24). Recuperado de http://elangelexterminador.com.ar/articulosnro.24/schlieper.html

Lois, É. (2005). De la filología a la genética textual. Historia de los conceptos y las prácticas. En F. Colla (coord.), Archivos. Cómo editar la literatura latinoamericana del siglo XX (47-83). París, Francia: CRLA-Archivos.

Manetti, R. y Rodríguez Riva, L. (Comps.). (2014). 30-50-70. Conformación, crisis y renovación del cine industrial argentino y latinoamericano. Ciudad Autónoma de Buenos Aires, Argentina: Editorial de la Facultad de Filosofía y Letras, UBA.

Meccia, E. (18 de septiembre de 2009). Mecha encendida. Página 12, suplemento Soy. Recuperado de https://www.p agina12.com.ar/diario/suplementos/soy/1-988-2009-09-18.html

Pauls, A. (1986). Manuel Puig. La traición de Rita Hayworth. Buenos Aires, Argentina: Hachette.

Puig, M. (2005). Querida familia: Tomo1.Cartas europeas (1956-1962). Buenos Aires, Argentina: Entropía.

Puig, M. (2007 [1973]). The Buenos Aires Affair. Buenos Aires, Argentina: Seix Barral.

Puig, M. (2011[1968]). La traición de Rita Hayworth. Buenos Aires, Argentina: Booket.

Rodas, G. (2011). Tres modos de expectación: personajes femeninos y cine en Boquitas pintadas. Folletín. Escritural (4). Recuperado de http://www.mshs.univ-poitiers.fr/crla/contenidos/ESCRITURAL/ESCRITURAL4/ES CRITURAL_4_SITIO/PAGES/Rodas.html

\section{Notas}

1 Al respecto, un dato cualitativo y anecdótico resulta el hecho de que frente a las 19 menciones que aparecen de la palabra gitano en la versión publicada de la novela, en el conjunto de manuscritos de la primera versión se cuentan un total de 34 . 
2 El proceso de escritura es, sin embargo, más complejo: "Si la novela que comenzó en 1962 se terminó de escribir en 1965, pero se siguió corrigiendo hasta su publicación en 1968, y aún después con una edición que incorpora importantes cambios en 1972, diez años después del 'accidente', vemos que la 'decisión plena, el rigor del comienzo' es lo que prevalece en un trabajo de reescritura permanente que sin embargo nunca se aleja de ese impulso primero, de esa fuerza emancipadora que Puig encuentra en las voces de sus tías y en las películas de su infancia recreadas veinticinco años después, en Roma" (Goldchluk, 2012, p. 334).

3 Si bien los detalles acerca de este episodio pueden recuperarse también en las cartas, resulta propicio recordar que la novela, ya terminada, no será publicada sino hasta 1968, por Jorge Álvarez, en Argentina.

4 "Los borradores, particularmente (con sus tachaduras, sustituciones verticales, desplazamientos, expansiones, yuxtaposiciones, interpolaciones, reducciones, interrupciones, conexiones, desgajamientos, intersecciones, etc.), ponen en primer plano las vacilaciones y los conflictos, y el texto en el que eventualmente desembocan no es más que una etapa provisoriamente "final"; a lo sumo, el producto específico de un conjunto de tendencias, pero jamás un resultado inevitable. La escritura avanza, retrocede, se dispersa o se reencauza; tiene, entonces, cierta “direccionalidad”, pero es una direccionalidad virtual" (2005, pp. 56-57).

5 Resulta interesante recordar que para la edición del volumen Materiales iniciales para la traición de Rita Hayworth se imprime este cambio a la publicación de los manuscritos, con la siguiente aclaración en nota al pie: "Para preservar la privacidad de las personas reales que intervienen en la historia, se ha recurrido a sustituir los nombres reales en los primeros bosquejos - en estado menos estilizado- por los nombres de ficción". Y se aclara: "En el caso de individuos que se mencionan en los bosquejos iniciales con nombres reales, pero que no tienen lugar en la ficción (y por lo tanto no tienen existencia literaria), se ha echado mano al recurso de indicarlos por medio de una inicial seguida de un punto" (Amícola, 1996, p. 23, el subrayado es mío). La frase “y por lo tanto no tienen existencia literaria” merece al menos una rápida mención en el contexto de estas páginas, en tanto implica la lectura de los papeles que implican el proceso de escritura de la obra por fuera de la literatura.

6 El material completo digitalizado, Colección Manuel Puig, se encuentra disponible en ARCAS: http://arcas.fahce.unl p.edu.ar/arcas/portada/colecciones/manuel-puig

7 El proceso de transcripción que llevamos adelante dentro del proyecto de investigación "El archivo como política de lectura. Reformulaciones teóricas y metodológicas en América Latina en torno a Archivos de escritores y artistas", dirigido por la Dra. Graciela Goldchluk (FaHCE-UNLP, H851), permite conjeturar la existencia de al menos cuatro versiones parciales, puesto que se conservan agrupados fragmentos iniciales de dos comienzos en la primera versión.

8 Este desanudar el tiempo para propiciar un distanciamiento podría pensarse en diálogo con la lectura de $L T R H$ como novela de aprendizaje (De Diego, 2000; Pauls, 1986).

9 "Quien intenta acercarse a su propio pasado sepultado tiene que comportarse como un hombre que excava. Ante todo, no debe temer volver una y otra vez a la misma circunstancia, esparcirla como se esparce la tierra, revolverla como se revuelve la tierra. Porque las "circunstancias" no son más que capas que sólo después de una investigación minuciosa dan a luz aquello que hace que la excavación valga la pena, es decir, las imágenes que, arrancadas de todos sus contextos anteriores, apareen como objetos de valor en los aposentos sobrios de nuestra comprensión tardía” (Benjamin, 2011, p. 128).

10 Ver especialmente Tesis V, VI y IX.

11 Sobre este aspecto resulta interesante la lectura efectuada por Giselle Rodas (2011) sobre Boquitas pintadas.

12 Leopoldo Torre Nilsson dirigirá Boquitas pintadas (1974), Raúl de la Torre, Pubis angelical (1982) y Héctor Babenco, El beso de la mujer araña (1985). Con cada uno de estos proyectos Manuel Puig entablará una relación particular.

13 Se trata de la obra de teatral escrita por Claire Booth, con la que en 1938 Mecha Ortiz se consagra en la escena nacional. Esta misma obra, The Women, será adaptada al cine y estrenada bajo la dirección de George Cukor en 1939. La película, por su parte, se encuentra dentro del repertorio más selecto de Manuel Puig; de hecho, un pasaje funciona como uno de los epígrafe de The Buenos Aires Affair (Puig, 2007, pp. 117-118), y la misma Mecha Ortiz figura también con otro dedicado a ella (Puig, 2007, p. 191), la única argentina de todo el star system reclutada en los epígrafes de la novela.

14 Con respecto a la relación Ortiz-Puig, resulta interesante acudir a una brevísima semblanza de la actriz, "Mecha encendida”, publicada por Ernesto Meccia (2009).

15 Ricardo Manetti explica que en la década del treinta el cine "elabora una maquinaria industrial asociada a otros sistemas de producción seriados (las revistas de cine, la radio, los discos, los espectáculos deportivos) con la intencionalidad de ofrecer al público un universo de valores que debe aprender como propios. Se consume pero se aprende” (2014, p. 27).

16 En este caso se trata del verso de un manuscrito de Pubis angelical. En todo el archivo aparecen una gran cantidad de listas de películas en diversos soportes, los criterios de agrupamiento y orden son variados, pero predomina el orden cronológico - donde la década del treinta es la más visitada- y de nacionalidad.

17 "El otro film informativamente se llama: Los muchachos de antes no usaban gomina. (Hay nombres informativos que son hermosos: El General murió al amanecer). Este-Los muchachos de antes, etcétera- es indudablemente uno de los mejores films argentinos que he visto: vale decir, uno de los peores del mundo. (...) El tema -el "nihilismo moral" o 
Orbis Tertius, vol. XXV, no 32, e172, noviembre 2020-abril 2021. ISSN 1851-7811

reblandecimiento progresivo de Buenos Aires- es, por cierto, atrayente. El director del film lo malogra (...).” (Borges, 1937, p. 101). 